\title{
The Impact of the Explicit Teaching of Three Particle Collocations on Reading Comprehension
}

\author{
Nasim Nobahar (Corresponding author) \\ Islamic Azad University, Science and Research Branch, Iran \\ E-mail: nasimnobah@gmail.com
}

Received: 07-10-2016

Published: 01-03-2017
Accepted: 12-12-2016

doi:10.7575/aiac.ijalel.v.6n.2p.173
Advance Access Published: January 2017

URL: http://dx.doi.org/10.7575/aiac.ijalel.v.6n.2p.173

\begin{abstract}
Research on collocations has been predominant for decades and decisive in debating the theoretical and pedagogical perspectives of collocations. Various approaches have been offered for best practices in teaching collocations. Despite this, we are yet to see an agreed-upon approach to teaching collocations. This study attempted to investigate the effect of explicit teaching of collocations. A further aim of the study was to see if test format affected the results. The results revealed that the explicit teaching of collocations had significantly improved the learners' knowledge of collocations. In addition, test format did have a noticeable effect on the results. Finally, a significant variation was observed among the learners as to their ability to learn collocations.
\end{abstract}

Keywords: Collocation, Vocabulary, Second language acquisition, Explicit teaching

\section{Introduction}

Research on collocations has been predominant for decades and decisive in debating the theoretical and pedagogical perspectives of collocations. The theoretical studies of collocations can be discussed from three perspectives: lexical, syntactic and semantic. Linguists elaborating collocations at the lexical level consider collocations as the linear and syntagmatic co- occurrence of lexical items (Mitchell, 1971). Collocations are also discussed in terms of their syntactic restriction (Nation, 2001) and semantic restrictions (Howarth, 1998; Lewis, 1997; Nation, 2001).

On the pedagogical level, linguists and language educators have conducted empirical studies on measuring collocational knowledge (Aghbar, 1990; Hsu, 2002; Zhang, 1993), development of collocational knowledge at different levels (Gitsaki, 1999), and discovering the common collocational errors that the second language learners make.

Language educators also provide methods of teaching collocations in the classroom. (Lewis, 2000; Woolard, 2000). This study is an attempt to shed some light on the effect of the explicit teaching of collocations on reading comprehension. A further aim of the study was to see if test format affected the results.

\section{Review of the related literature}

Vocabulary is the heart of a language and learning a language is revolving around vocabulary which is undeniable and taught by teachers in various ways implicitly or explicitly. The last couple of decades has witnessed a growing emphasis on the role of vocabulary in language teaching and learning. As Hunt and Beglar (2005) argue, "the heart of language comprehension and use is the lexicon", an idea shared by Lewis (2000) who states that "the single most important task facing language learners is acquiring a sufficient large vocabulary".

It is quite expected that learning vocabulary items in isolation may not help the learners gain the ability to use these individual items in real life communicative interactions. What is needed is the ability to combine new words in phrases and collocations.

The concept of collocations has been defined variously by different scholar but one of the most commonly offered definition of collocations is the tendency of one word to co-occur with one or more other words in a particular domain (Hsu, 2007; Nesselhauf, 2003). In a similar vein, Lewis (2000) argued that collocations may play a more important role in accuracy than even grammar. A knowledge of collocational items may also help expand language learners' mental lexicon (Forquera, 2006) their memory.

The fundamental question given vocabulary by teachers is "what does it mean to learn a word?" A definition of learning a word deeply depends on what we mean by a word, how a word is remembered for a length of time, in what circumstances it can be recalled (after a short time) or retained (after a long time). Some even have argued that knowledge of vocabulary items may be the most important aspect of language ability (Knight, 1994). While very little can be conveyed without grammar, nothing can be conveyed without vocabulary (Wilkins, 1983).

Based on this view, grammar is just another kind of collocation and language chunks account for idiomaticity of language. Lewis argues that language consists of grammaticalized lexis, not lexicalized grammar.

The theory of language underlying the lexical approach is against Chomsky's theory of generative linguistics which has 
syntax at its core and argues that the ideal native speaker uses this knowledge to produce an endless number of unique sentences. On the other hand, the lexical view holds that only a small part of language is unique to the speakers and what is more important is the fact that the majority of produced sentences are just repetitious use of chunks and lexical phrases. Albeit, the lexical approach seems to agree with more recent models of Chomsky on linguistics, namely the "minimalist program".

Lewis's lexical approach and the lexical syllables of Willis have a number of common features. Both believe that vocabulary has function through meaning and both were against traditional distinction between vocabulary and grammar. From their point of view, words are really "small grammar" and grammar is "big words". However, they have different classroom approaches. Willis is in favor of task-based learning for their meaning based syllabus.

According to Halliday (1966), lexis and grammar are interwoven rather than isolated items. Vocabulary items are not always single items or simply "context words". Moreover they can involve multi word units such as idioms, clichés or fixed expression that have both a consistency of form and meaning (Cruse, 1984).

Conventionally, vocabulary was taught as a single item, regardless of the relationship among surrounding words in a text. However, it is becoming increasingly proved that only knowledge of words in "isolation" appears "insufficient" for English vocabulary mastery.

One of the most significant controversial issues in a second or foreign language is collocations as a complicated attribute of second language learning and as an indispensable element of communicative competence.

The first scholar to highlight the role of vocabulary was Palmer (1933). He argued in his monograph that teaching individual lexical items in a second language may not be the most efficient method of vocabulary teaching. A more efficient option may be considering the lexical phrases as single units and teaching them as such.

Therefore, some scholars have argued that language ability may be in essence just vocabulary knowledge (Gass, 1999) and language teachers may better focus on this aspect of language proficiency more in their day to day teaching practice.

According to Marzban and Kamalian (2013) implicit and explicit learning have some features as below:

Implicit:

- $\quad$ No attention on the part of learners is allocated directly on the information to be learned.

- $\quad$ No conscious operations on the part of learners are involved in the learning process.

- Learners are unaware of the process of learning, information to be learned and of the result of knowledge from the learning process.

Explicit:

- $\quad$ Learners focus their attention explicitly on the information to be learned.

- Conscious operations on the part of learners are involved in the learning process.

- Learners are aware of the process of learning, of the information to be learned and of the result knowledge from the learning process.

Winter and Reber (1994) believe that implicit learning means the notion that people can under some circumstances absorb knowledge or information from the environment without awareness of the learning process. But explicit learning means allocation of attention directly on the information to be learned.

It seems that not many studies have been devoted to the comparative effectiveness of implicit and explicit teaching of collocations. This is needed because the studies have been mostly done in different contexts and with different participants. Hence the comparability of the results may be dubious. Thus, the present research investigates and compares the effects of these two approaches. Specifically, the following research question is posed:

Does collocation instruction based on explicit teaching of collocation have any effect on reading comprehension?

One of the important factors that may affect the performance of the participants is test format. Hence, in order to investigate the possible effect of test format, the following research question was also posed:

Does test format make any difference?

\section{The study}

\subsection{Participants}

The research took place at a private institute in Iran. Out of the pool of participants available in the institute, 30 female students, ages ranging between 20 and 45 participated in the study.

At Intermediate level learners got specific and explicit instructions on collocations, after finishing their specific course book (New Headway Fourth Edition). Each term consisted of twenty sessions, each session lasted one hour and a half, the study exercised after students' main instruction given their book then work on target collocations. These collocations were chosen from higher levels in the same series of New Head way Upper Intermediate and FCE.

\subsection{Instrumentation}

The following materials were used in the study.

A PET Standard English Language Test was administered to check the homogeneity of the subjects. This was needed 
because without being sure that the participants are homogenous, any following interpretation of the results may be unjustified.

Thirty collocations in a pre-test were given to the students to spot what they knew or did not know. The study was used with following instruments: Vocabulary knowledge scale, vocabulary pretest, collocations instruction, comprehension questions

A post-test was given to assess which instruction was more effective. This test was "teacher made" - i.e. to "fill in the blanks", Reading comprehension and close tests.

\subsection{Procedure}

At the beginning of the study, a pet exam was constructed to homogenize students. Second, in order to determine the syllabus for the treatment sessions, Vocabulary Knowledge Scale (VKS), implemented which were adopted from Peribakht and Wesche $(1993,1996)$. The VKS was a five point scale self -report test measuring lexical knowledge on a continuum from no knowledge to the ability to produce the target word accurately in a sentence. This test is used to determine prior knowledge of the target items by learners (Kim, 2008; Nassaji \& Tian, 2010; Paribakht \& Wesche, 1996; Read \& Chapelle, 2001).

The participants scored their knowledge of the targeted items on a scale from 1 to 5 as follows:

1. I don't remember having seen this word before.

2. I have seen this word before, but I don't know what it means.

3. I have seen this word before, and I think it means ............. (synonym or translation).

4. I know this word. It means................... (synonym or translation).

5. I can use this word in a sentence (write a sentence)

Third, the vocabulary pretest was administered. This test was compromised of thirty fill in the blanks possible target items from the reading passage or what was taught during the term. The contextualized sentences were adopted from Longman Contemporary for Advance Learners. The aim of the test was to determine prior knowledge of the target items by learners in addition to the Assessing Vocabulary Scale.

The fourth step included the collocations instruction. Three particle Collocations: "verb+ preposition+ preposition "was used in one class only with contextualizing and giving a synonym and many examples of collocation, for instance who can get on well with all different people with various manners? Can you tolerate people who are lying? Can you put up with someone who is arrogant? Providing sentences regarding the target items usually three collocations each session. After explicit instruction and examples, the instructor elicited examples from the participants. The treatment lasted for approximately 30 minutes.

In another class three collocations were selected to be taught. The instructor gave explicit dictionary definitions of the target items, and provided sentences regarding the target collocation .Example sentences were retrieved from Longman Contemporary Dictionary for advanced students. After the explicit instruction and examples, the instructor elicited examples from participants. The treatment lasted for nearly 30 minutes.

Reading passage: The reading passages were chosen from New Head Way Course book and also from previous course books utilized at Kish Institute." Total English". The reading comprehension test met these three criteria: length, number of collocations, and level of difficulty (Hsu, 2010).

Comprehension questions: three reading comprehension questions were asked targeting the collocations taught. Five questions targeted the collocations and one question was the distracter. The questions were designed to specifically elicit the target items.

One class after treatment was assessed by reading comprehension which included collocations. Another class after treatment was evaluated by to being asked fill in the gaps, sentences were chosen from the Longman Contemporary Dictionary.

\section{Results}

As it was explained in earlier, two types of tests were developed. The first test was in the form of a Fill-in-the-Blank test and the second test contained a couple of reading texts in which the collocations were included. For each reading text, a couple of questions (i.e., 30 items) were developed. The items were developed in a way that a correct response would require understanding one of the collocations.

The Fill in the Blank and Reading tests were given to two independent groups. Each test included thirty items. The performance of the two groups on the Fill in the Blank and Reading tests are graphically displayed in Figure 1 and Figure 2 respectively.

Figure 1 reveals that some items (e.g. Item 26) has not been correctly answered by any of the participants. On the other hand, all participants have correctly answered Item 19. On the whole, it seems that the participants' performance on the test has not been superb considering the fact that all collocations were taught during the course. 


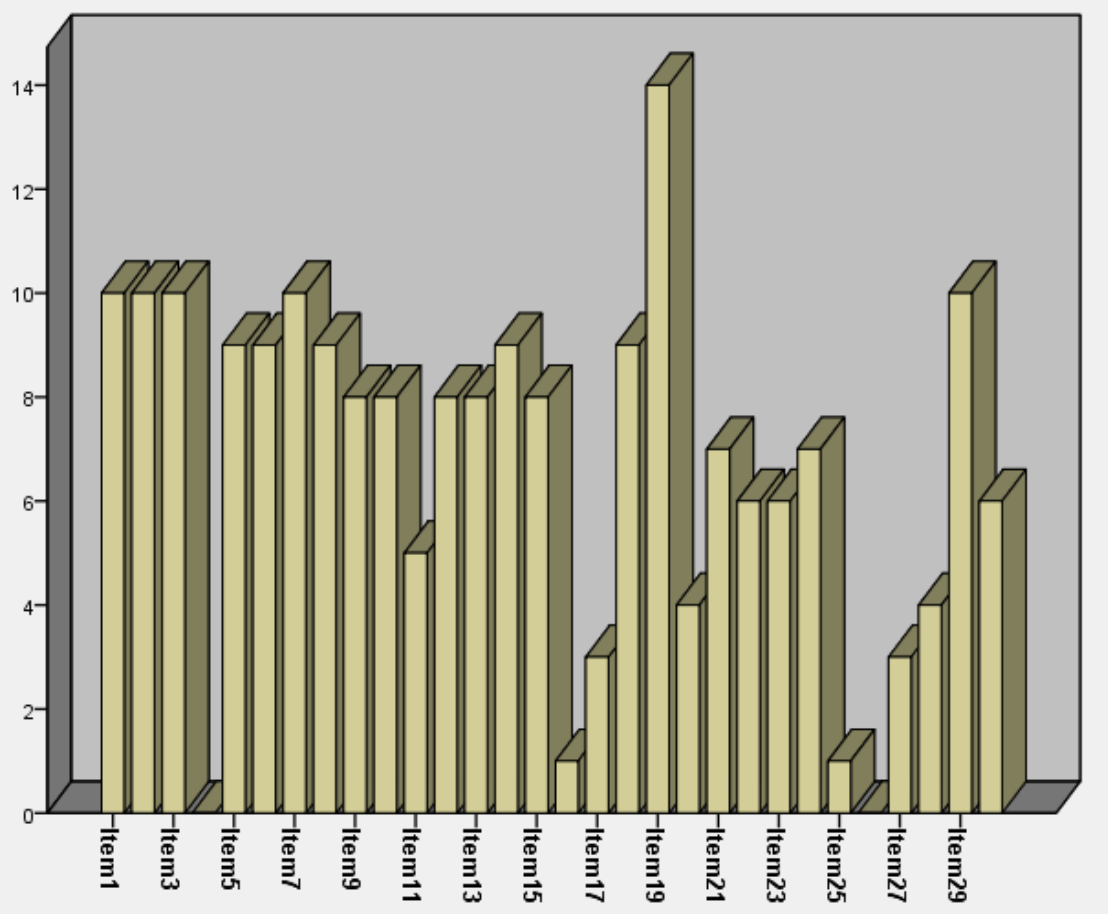

Figure 1. Performance on the Fill in the Blank Test

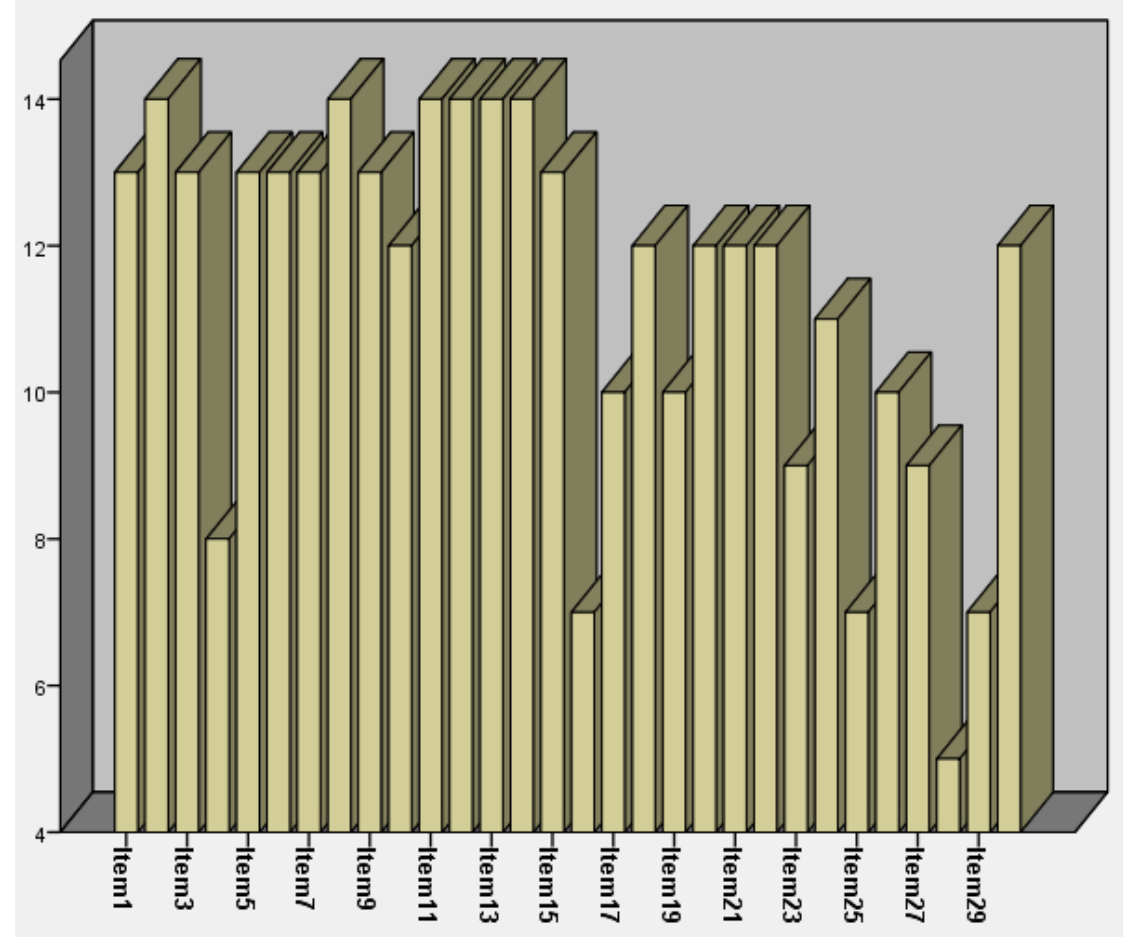

Figure 2. Performance on the Reading test

The descriptive statistics for the two groups are displayed in Table 1. Note that there are 15 participants in the first group and 14 participants in the second. On the Fill in the Blank test, the mean score is about 13.46. The mean score on the Reading test is 24.28 . Hence, it is clear that the participants have had a better performance on the Reading test.

Table 1. Descriptive statistics for the two tests

\begin{tabular}{llllllll}
\hline Group & $\mathrm{N}$ & Range & Minimum & Maximum & Mean & Std. \\
\hline Fill in the blank & 15 & 13.00 & 8.00 & 21.00 & 13.4667 & 3.44065 & 11.838 \\
Reading & 14 & 12.00 & 18.00 & 30.00 & 24.2857 & 3.45139 & 11.912 \\
\hline
\end{tabular}

So far, we have some evidence that there is a difference between the performance of the participants on the two tests. In order to evaluate the statistical significance of this difference, an independent-samples t-test was run. However, before running the t-test, the normality of the data was checked. The indices in Table 2 reveal that the data is close to normal. 
First of all, the trimmed means are very close to actual means which indicates that there is no outlier effect. In addition, the Skewness and Kurtosis indices do not indicate violation of the normality assumption.

Table 2. Normality indices

\begin{tabular}{|c|c|c|c|c|}
\hline \multicolumn{3}{|l|}{ Group } & \multirow{2}{*}{$\begin{array}{l}\text { Statistic } \\
13.4667\end{array}$} & \multirow{2}{*}{$\begin{array}{c}\text { Std. Error } \\
.88837\end{array}$} \\
\hline Fill in the Blank & Mean & & & \\
\hline & $\begin{array}{l}95 \% \text { Confidence Interval for } \\
\text { Mean }\end{array}$ & $\begin{array}{l}\text { Lower } \\
\text { Bound }\end{array}$ & 11.5613 & \\
\hline & & Upper Bound & 15.3720 & \\
\hline & $5 \%$ Trimmed Mean & & 13.3519 & \\
\hline & Median & & 13.0000 & \\
\hline & Skewness & & .379 & .580 \\
\hline & Kurtosis & & .144 & 1.121 \\
\hline \multirow[t]{7}{*}{ Reading } & Mean & & 24.2857 & .92242 \\
\hline & $\begin{array}{l}95 \% \text { Confidence Interval for } \\
\text { Mean }\end{array}$ & $\begin{array}{l}\text { Lower } \\
\text { Bound }\end{array}$ & 22.2929 & \\
\hline & & Upper Bound & 26.2785 & \\
\hline & $5 \%$ Trimmed Mean & & 24.3175 & \\
\hline & Median & & 24.5000 & \\
\hline & Skewness & & -.072 & .597 \\
\hline & Kurtosis & & .090 & 1.154 \\
\hline
\end{tabular}

The final step in checking the normality of the data was to run the Kolmogorov-Smirnov and Shapiro-Wilk tests. The results are reported in Table 3. Both tests indicate that the data is normal. Therefore, the independent-samples t-test can be run.

Table 3. Normality tests

\begin{tabular}{llllllc}
\hline Group & \multicolumn{5}{l}{ Kolmogorov-Smirnov } & \multicolumn{5}{l}{ Shapiro-Wilk } \\
\hline \multirow{3}{*}{ Fill in the Blank } & Statistic & df & Sig. & Statistic & df & Sig. \\
\cline { 2 - 7 } Reading & .139 & 15 & .200 & .968 & 15 & .833 \\
\hline
\end{tabular}

The results of the independent-samples t-test are reported in Table 4. Note that the Leven's test is not significant. Hence, the assumption of the equality of the variances is not rejected. Therefore, the first row of the table must be interpreted. Here, it turns out that the t-test is significant. Therefore, the difference between the performance on the two tests is statistically significant.

Table 4. Independent-samples t-test results

\begin{tabular}{|c|c|c|c|c|c|}
\hline & \multicolumn{2}{|c|}{$\begin{array}{l}\text { Leven's Test for Equality of } \\
\text { Variances }\end{array}$} & \multicolumn{3}{|c|}{ t-test for Equality of Means } \\
\hline & $\mathrm{F}$ & Sig. & $\mathrm{t}$ & Df & Sig. (2-tailed) \\
\hline Equal variances assumed & .064 & .802 & -8.449 & 27 & .000 \\
\hline \multicolumn{3}{|l|}{ Equal variances not assumed } & -8.448 & 26.850 & .000 \\
\hline
\end{tabular}

In order to make sure that the statistical significance of the t-test is not due to chance factors, the eta squared effect-size index was calculated. The index turned out to be 0.73 . Based on Cohen's (1988) guidelines, this indicates a large effect. Hence, there is ample evidence that the performance of the participants on the Fill in the Blank and Reading tests is different. 


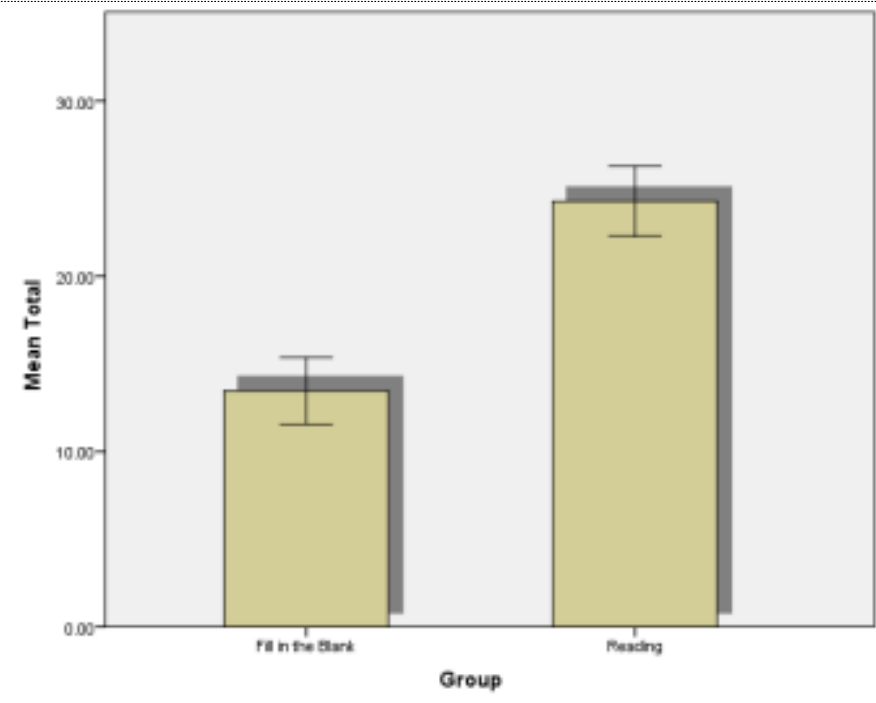

Figure 3. Mean Scores on the Two Tests

The difference between the performance of the participants on the two tests is more clearly observed in Figure 3 . Note that there is big gap between the two bars even after the confidence intervals are taken into account.

\section{Discussion \& Conclusion}

A number of insights can be gained from the results of the study. First, it is clear that in both groups some noticeable learning has happened. This is clear from the fact that the learners did not know any of the collocations at the beginning of the course. However, it is clear from the results that their knowledge of the items is far from zero at the end of the course. This holds true for both groups of participants taking either the Fill in the Blank test or the Reading test. Hence, it is evident that the explicit instruction of collocations does a significant job in collocation learning.

The results are in keeping with the suggestions of Gass (1999). She suggested that in the explicit teaching of collocations, the learners were allowed to benefit from a couple of resources. For instance, they can use the dictionary to get a grasp of the exact meaning of the collocation. Also, they may be allowed to look for synonyms and antonyms which help foster the knowledge base.

Another way in which the explicit teaching of collocations can help is that they are provided with the opportunity to notice the collocations. The noticing hypothesis, as proposed by (Schmidt, 1990), argues that the input that the learners receive in any form will not be learnt or become part of their knowledge store unless it is noticed. According to this view, if we want to teach any aspect of language, we have to devise strategies to help the learners notice the point we are making. Hence, in the case of collocation teaching, for instance, the explicit teaching of collocations will be an efficient strategy because it helps the learners notice the collocations.

Another reason that the explicit teaching of lexical items may prove to be useful is the fact that while teaching the collocations the teacher has to provide an explanation of the individual items included in the single collocation item and any related vocabulary. This way, not only the collocation itself is explicitly taught, but the related vocabulary is also explained. Consequently, when the learners see the collocation, they know the meaning of the individual items included in the collocation (Hunt \& Beglar, 1998). Therefore, they are at a better position to guess the meaning of the entire collocation as a whole. Note that this is particularly helpful in the case of the receptive recognition of collocations which is exactly the case with the current study.

All in all, the results reveal that the explicit teaching of collocations does in fact result in learning and this is in keeping with the following studies among others: Aghbar (1990), Bahns, (1993), Hsu (2010), Seesink, (2007), and Siyanova and Schmitt, (2008).

Despite the fact that the explicit instruction of collocations is helpful, this is also evident from the results of the present study that the participants do not learn the collocations equally well. This is apparent from the bar graphs in the beginning of the chapter. For example, Item 19 has been answered correctly by almost all of the participants taking the Fill in the Blank test. Also, Item 13 has been correctly answered by all participants taking the Reading test. But not all items have been so easy. There are items that are not correctly answered by any of the learners. Examples are items 4 and 26 in the first group. Other items have item facilities between these two extremes. Hence, it is apparent that individual items pose a source of variation and the amount of variation brought by individual items is not negligible at all.

Another source of the variation in the scores seems to be, as expected, the differential performance of the participants themselves. An inspection of the individual scores reveals that there is wider variation on the amount of learning on the part of participants. This is also clear from the range of 13 and 12 on the Fill in the Blank and Reading tests respectively. The range, as explained earlier, shows the different between the highest and lowest scores, which is a rather large score in this case. 
Such a wide range is rather unexpected considering the fact that the neither of the participants knew any of the collocations at the beginning of the course. In fact, it was checked before the start of the course that collocations are not already familiar to the students because this would beg the question.

In fact, a plethora of factors play a role in test performance. Bachman $(1990, \mathrm{p} .164)$, for instance, argues that "communicative language ability, personal attributes which are not part of language abilities we are interested in, random factors which are unpredictable and temporary, and test method facets". Any of these factors may play a significant role in a given testing occasion. Therefore, some variation is expected from one context to another.

The effect of the learner characteristics on test performance is evident from the findings of the present study. As explained above, it appeared that there is a wider variation among the participants considering their scores on both the Fill in the Blank and Reading tests. In the absence further empirical research, however, it would be quite impossible to know what specific test taker characteristics affect performance in a specific study.

The effect of the 'test method facets' on test performance has also been investigated widely. Bachman (1990) gives a very detailed account of the aspects of the test that may affect the test taker's performance. Of course, Bachman (1990) is not the first scholar to have noted these facets and their effect on test performance.

The five major test method facets introduced by Bachman (1990) are the following:

1. Testing environment

2. Test rubric

3. The nature of the input the test taker receives

4. The nature of the expected response

5. The relationship between input and response.

The 'test method facets' seem to have played an important role in the current study. This appears from the results of independent-samples t-test displayed in Table 4. It appears from the table that there has been a significant difference between the performance of the participants on the Fill in the Blank and Reading tests. In fact, it is clear from the descriptive statistics reported in Table 1 that there is an about 11-score difference between the performance of the test takers on the two tests and that participants taking the Reading test have outperformed those taking the Fill in the Blank test.

One of the factors that Bachman (1990) identifies in his delineation of the 'test method facets' is the 'nature of input'. Under this facet, Bachman (1990) included a couple of factors. One of the major factors which is relevant to the present discussion is the 'nature of language' under which comes 'degree of contextualization' which, as Bachman (1990) argues, can be either 'embedded' or 'reduced'. It seems that this factor boils down to what is commonly known as the 'effect of context'.

In fact, there is a large body of research on the effect of context on inferring the meaning of words and collocations. Takac (2008, p. 17), for instance, argues that "context-based inferencing contributes to the knowledge of morphological rules, collocations, additional meanings (for it is the context that determines the meaning of a lexical unit), etc."

McKoon and Ratcliff (1992) argued that there are two types of inferences. Local inferences involve pieces of explicitly stated information close to each other while global inferences are related to separate pieces of information in a text. Hence, in a reading comprehension text, for examples, the relevant information (i.e., knowledge sources) needed for inferencing need not be in the vicinity of the specific lexical item. However, the important point is that these knowledge sources are available to the readers.

This may account for the differential performance of the participants in the present study on the Fill in the Blank and Reading tests. It is clear that there is little context available in the case of the Fill in the Blank test. In fact, the standard books on designing and developing language tests (e.g., Farhady, Jafarpur, \& Birjandi, 2003; Hughes, 2003) require that there must be little contextual clues in the Fill in the Blank tests. Hence, these tests, by their very nature, lack the kind of contextual clues available in the Reading tests.

Hence, it seems that the availability of knowledge sources in the Reading tests is at least one of the factors that may account for the fact that the participants taking this test have outperformed the participants taking the Fill in the Blank test.

In addition, Wesche and Paribakht (2010) noted that the participants in their study utilized sentence-level knowledge sources the most when making lexical inferences in both their L1 and L2 reading. Interestingly, they also argued that the participants revealed differences in percentages of the use of other knowledge sources in lexical inferencing. This finding may account for the individual differences in the scores among those test takers who took the Reading test. Specifically, the participants in their study did not necessarily use the same knowledge sources even when such information is available.

Therefore, it seems that due to a myriad of individual differences the degree of lexical inferencing is not the same for all individuals (Nassaji, 2006). Hence, if the availability of contextual clues in the Reading test is the main factor explain the difference performance of the test takers, such individual variation can also be attributed to, among many other factors, the individual differences in inferencing. 


\section{References}

Aghbar, A. A. (1990). Fixed expressions in written tests: Implications for assessing writing sophistication. East Lansing, MI: National Center for Research on Teacher Learning. (ERIC Document Reproduction Service No. ED 352808).

Bahns, J. (1993). Lexical Collocation. A Contrastive View. ELT Journal, 47(1), 56-63.

Cohen, J. (1988). Statistical power analysis for the behavioral sciences (2nd ed.). Hillsdale, NJ: Lawrence Earlbaum Associates.

Cruse, D.A. (1986). Lexical Semantic. New York: Cambridge University Press.

Ellis, N. (1994). Implicit and explicit language learning - an overview. In N. Ellis (ed.), Implicit and Explicit Learning of Languages. London: Academic Press, 1-31.

Farhady, H. Jafarpur, A., \& Birjandi, P. (2003). Testing language skills: From theory to practice (10th ed.). Tehran: SAMT.

Forquera. D. (2006). Goodbye foreign flavor. The hows and whys of teaching Collocations. Paper presented at the second national meeting of teacher training colleges. Retrieved March 2, 2016, from http://WWW.Danielaforquera.com.ar/docs/Handut.pdf

Gass, S. (1999). Discussion. Studies in Second Language Acquisition, 21(02), 319-333.

Gitsaki, C. (1999). Second language lexical acquisition: A study of the development of collocational knowledge. Bethesda, MD: International Scholars Publications.

Halliday, M. (1966). Lexis as a linguistic level in C. Bazell, J. Catford, M. Halliday and Robins (Eds.). In memory of J. R. Firth. (148-162). London: Longman.

Howarth, P. (1998). Phraseology and second language proficiency. Applied Linguistics, 19(1), 22-44.

Hsu, J. (2002). Development of collocational proficiency on a workshop on English for general business purposes for Taiwanese college students. Unpublished doctoral dissertation, Indiana University of Pennsylvania, Pennsylvania.

Hsu, J-Y. (2007). Lexical collocations and their relation to the on line writing of Taiwanese college English majors and Non-English majors. Electronic Journal of foreign Language Teaching, 4(2), 192-209.

Hsu, J-Y. (2010). The effects of collocations instruction on the reading comprehension and vocabulary learning of Taiwanese college English majors. Asian EFL journal, 12(1), 47-87.

Hughes, A. (2003). Testing for language teachers. Cambridge: Cambridge University Press.

Hunt, A. \& Beglar, D. (2005). A frame work for developing EFL reading vocabulary. Reading in a foreign Language, 17(1), pp.23-59.

Kim, Y. (2008). The contribution of collaborative and individual tasks to the acquisition of L2 vocabulary. Modern Language Journal, 92, 114-30.

Lewis, M. (1993). The lexical Approach. London: Language Teaching Publication.

Lewis, M. (1997). Implementing the lexical approach: Putting Theory into practice. London: Language Teaching Publication.

Lewis, M. (2000). Teaching collocation: Further Developments in the Lexical Approach. Hove, England: Language Teaching Publications.

Marzban, A., \& Kamalian, K. (2013). Effects of implicit versus explicit vocabulary instruction on intermediate EFL learners' vocabulary knowledge. ELT Voice, 3(6), 84-95.

McKoon, G., \& Ratcliff, R. (1992). Inference during reading. Psychological Review, 99(3), 440-466.

Mitchell, T. F. (1971). Linguistics going on: Collocations and other lexical matters on the syntagmatic record. Archivum linguisticm, 2, 35-64.

Nassaji, H, \& Tian, J. (2010). Collaborative and individual output tasks and their effects on learning phrasal verbs. Language Teaching Research, 14(4), 397-419.

Nassaji, H. (2006). The relationship between depth of vocabulary knowledge and 12 learners' lexical inferencing strategy use and success. The Modern Language Journal, 90, 387-401.

Nation, P. (2001). Learning vocabulary in another language. Cambridge: England; Cambridge university press.

Nesselhauf, N. (2003). The use of collocations by advanced learners of English and some implications for teaching. Applied linguistics, 24(2), 223-242.

Palmer, H. E. (1933). Second interim report on English Collocations. Tokyo: Kaitakusha.

Paribakht, S. \& Wesche, M. (1996). Enhancing vocabulary acquisition through reading: A hierarchy of text-related exercise types. Canadian Modern Language Review, 52, 155-78.

Read, J. \& Chapelle, C. (2001). A framework for second language assessment. Language Testing, 18, 1-32.

Schmidt, R. (1990). The role of consciousness in second language learning. Applied linguistics, 11, 129-158. 
Schmitt, N. (2008). Review article: Instructed second language vocabulary learning. Language Teaching Research, 12(3), 329-363.

Seesink, M. T. (2007). Using Blended Instruction to Teach Academic Vocabulary Collocations: A Case Study. Unpublished Doctoral Dissertation, West Virginia University.

Siyanova, A., \& Schmitt, N. (2008). L2 Learner Production and Processing of Collocation: a Multi-Study Perspective. Canadian Modern Language Review, 64(3), 429-458.

Takac, V. P. (2008). Vocabulary Learning Strategies and Foreign Language Acquisition. Clevedon, Buffalo, Toronto: Multilingual Matters LTD.

Wesche, M. B., \& Paribakht, T. (2010). Lexical inferencing in a first and second language: Cross-linguistic dimensions. Bristol: Multilingual Matters.

Wilkins, D. A. (1983). Linguistics in Language Teaching. London: Edward Arnold.

Winter, B. \& Reber, A. S. (1994). Implicit learning and the acquisition of natural languages. In N. C. Ellis (Ed.), Implicit and explicit learning of languages (pp. 115-145). London: Academic Press.

Woolard, G. (2000). Collocation - encouraging learner independence. In M. Lewis (Ed.), Teaching collocation: Further developments in the lexical approach (pp. 28-46). London: Language Teaching Publications.

Zhang, X. (1993). English collocations and their effect on the writing of native and non-native college fresh-men. Unpublished doctoral dissertation, Indiana University of Pennsylvania, Pennsylvania, USA. 